\title{
Built-up area analysis using Sentinel data in metropolitan areas of Transylvania, Romania
}

\author{
Constantin OŞLOBAnU and Mircea AlEXE ${ }^{1}$
}

\begin{abstract}
The anthropic and natural elements have become more closely monitored and analysed through the use of remote sensing and GIS applications. In this regard, the study aims to feature a different approach to produce more and more thematic information, focusing on the development of built-up areas. In this paper, multispectral images and Synthetic Aperture Radar (SAR) images were the basis of a wide range of proximity analyses. These allow the extraction of data about the distribution of built-up space on the areas with potential for economic and social development. Application of interferometric coherence and supervised classifications have been accomplished on various territories, such as metropolitan areas of the most developed region of Romania, more specifically Transylvania. The results indicate accuracy values, which can reach 94 per cent for multispectral datasets and 93 per cent for SAR datasets. The accuracy of resulted data will reveal a variety of city patterns, depending mainly on local features regarding natural and administrative environments. In this way, a comparison will be made between the accuracy of both datasets to provide an analysis of the manner of built-up areas distribution to assess the expansion of the studied metropolitan areas. Therefore, this study aims to apply well-established methods from the remote sensing field to enhance the information and datasets in some areas lacking recent research.
\end{abstract}

Keywords: backscattering, metropolitan areas, supervised classification, urban footprint, built-up area

Received February 2021, accepted March 2021

\section{Introduction}

Current geographic studies attempt to follow as accurately as possible the different natural and anthropogenic phenomena in the world. In this direction, different geographic branches develop techniques for processing and interpreting geographic information, such as satellite data. A good example would be the European Space Agency (ESA) data acquired by the remote sensing satellites, Sentinel-1 and Sentinel-2. European satellite data presents the best performance regarding opensource multispectral images at a spatial resolution of $10 \mathrm{~m}$. ESA occupies an important position, and its data are being studied and analysed by various researchers (KoppeL, K. et al. 2015; Khalil, R.Z. and Haque, S.U. 2017;
ZAKERI, H. et al. 2017) to approach the results of high-resolution Synthetic Aperture Radar (SAR) platforms. Therefore, extensive studies were accomplished using different types of classifications (e.g., Corbane, C. et al. 2017) and exploiting Landsat multispectral images and Sentinel SAR images for the global mapping of human settlements, using Global Human Settlement Layer, which includes global multi-temporal evolution (1975, 1990, 2000 and 2014) of built-up surfaces.

Studying the expansion of the built areas, different methods have been applied. One of these methods is represented by the normalized difference indices: Normalized Difference Built-up Index (NDBI) and Normalized Difference Vegetation Index (NDVI) (ZHA, Y. et al. 2003). Then the technique evolved, creat-

\footnotetext{
${ }^{1}$ Faculty of Geography, GeoTomLab, Babeş-Bolyai University, 5-7, Clinicilor Street, 400006 Cluj-Napoca, Romania. E-mails: mircea.alexe@ubbcluj.ro (corresponding author), constantinoslobanu@yahoo.ro
} 
ing new indices based on either the thermal band (As-Syakur, A.R. et al. 2012) or on the analysis of built-up areas on extended surfaces using a group of built-up indices ( $\mathrm{LI}, \mathrm{H}$. et al. 2017) or combining several vegetation, water and built-up indices to reduce confusions (XU, H. 2010). Afterwards, these validated indices begin to be used in studies for measurements of the built space (KaIMARIS, D. and Patias, P. 2016).

Another variant of emphasizing the built-up areas is the one in combination with other land use classes (Yuan, F. et al. 2005; Dewan, A.M. and Yamaguchi, Y. 2009). In this category, most of the studies (SEKERTEKIN, A. et al. 2017; Forkour, G. et al. 2018) generated maps using supervised classification method (Maximum Likelihood Classification, MLC) based on Landsat scenes, then comparing the results with Corine Land Cover (CLC). Apart from using land cover datasets, other digital resources may be used for mapping urban areas, such as high-resolution imaging studies, orthophoto maps, the Google Earth data catalogue or even images acquired by the drones. The approach based on supervised classifications was developed even on large surfaces $\left(\mathrm{MA}_{\mathrm{A}} \mathrm{Y}\right.$. and $\mathrm{X}_{\mathrm{U}}, \mathrm{R} . \mathrm{2010}$ ) or on long-term models of maps (Padmanaban, R. et al. 2017) using optical data.

Similar to the trend of the universal scientific literature in the field, the tendencies from Romania approaches the same remote sensing elements for studying space in the extra-atmospheric environment. On this subject, a bunch of research concentrated on the biggest city, the capital of the state, Bucharest. The main trend in the Romanian literature was to analyse urban expansion using supervised classifications from Landsat scenes and then comparing with CLC data and applying buffers every $5 \mathrm{~km}$ to observe the evolution of all elements in the territory (Minai, B. et al. 2015), but there were authors who also relied on high-resolution panchromatic and multispectral images, like CORONA and IKONOS imagery (SANDRIC, I. et al. 2007). In the same period, more complex subjects were applied by other authors, such as the Principal Component Analysis (PCA) method on Landsat and SPOT multispectral images or SAR data (ZorAn, M. and Weber, C. 2007). Another example is the comparison of Bucharest city with French Guyanese areas, using the fusion of optical data and SAR data with high-resolution (CorbANE, C. et al. 2008).

The MLC is a supervised method, which assumes that the user identifies by visual analysis, polygons of pixels or groups of pixels, defining the ranges of spectral values that have a correspondent in phenomena or objects in the real environment. Then, the classifier determines according to statistics which pixel is assigned to a certain class that has the highest probability to be normally distributed. Other supervised methods (LiLlesand, T.M. and Kiefer, R.W. 1994) use mean vectors, such as Minimum Distance method and classifies pixels to the nearest class based on Euclidean distance or such as Parallelepiped classification based on n-dimensional parallelepiped, where each pixel is assigned to a certain class defined by the standard deviation threshold from the mean of each identified class. The MLC is preferred by some authors for several of regions from Romania, such as the Iași Metropolitan Area (Cîmpianu, C. and Corodescu, E. 2013), the Brașov Metropolitan Area (VorovenciI, I. 2017) or the Constanța Metropolitan Area (Corodescu, E. and Cîmpianu, C. 2014). Also, the use of NDVI or NDBI is appropriately accomplished on small human settlements, such as Lugoj Municipality and surrounding area (COPĂCEAN, L. et al. 2015) and for those located in various natural conditions, in the mountainous area or the areas with a temperate marine climate, near the Black Sea lagoons (Huzu, A.E. et al. 2012). Besides, optical data is also used to identify agricultural land conversions to Argeş County (Kuemmerle, T. et al. 2008).

Various elements of cartographic representation methods have been treated in other research papers, such as cartograms and buffers. (EEA, 2006; Grigorescu, I. et al. 2012). It is in regard to cartogram maps with annual surface growth rates of the built-up area at administrative-territorial unit (ATU) level within the Metropolitan Area of Bucharest (Grigorescu, I. et al. 2014). For better at- 
tainment of this method, this study will use cartogram maps for comparing the built-up area percentages resulted from processing multispectral datasets and also SAR datasets.

Regarding the most important studied area, which is in full economic and social growth, Cluj-Napoca Metropolitan Area, this is more intensively studied through the perspective of the national university center present in this city. Thus, in this area, it encounters various spatial-space studies such as the spatial-temporal expansion of impermeable surfaces using the Landsat data for supervised classifications (IvAN, K. 2015) or the extraction of built-up areas using texture analysis of SAR images combined with unsupervised classification Sentinel images (HolobÂcă, I.H. et al. 2019).

Other studies (Mucsi, L. et al. 2017) are focusing on using more precise instruments (e.g., hyperspectral aerial image) for accurate detection of anthropogenic elements. It has reached a level where SAR images are increasingly exploited in geographic and interdisciplinary studies by using interferometric coherence (Koppel, K. et al. 2015). The access to data that provides such SAR information has become insignificant, achieving even semi-automatic and fully automated urban area classification (Urban Footprint Processor, UFP) methods using SAR images with TanDEM X (Esch, T. et al. 2013). However, the current trend is to produce the highest degree of accuracy using all types of data made available, of good and very good precision. Sentinel and Landsat satellites are the main providers of such data. Processing these spatial data, standards of accuracy can be achieved with a small number of classes, urban - non-urban and through more complex methods. This type of technique can be performed using advanced computer algorithms such as Symbolic Machine Learning - SML (Pesaresi, M. et al. 2016).

This study aims to highlight natural and human influences on the development of different urban settlements. This purpose was achieved using methods such as Maximum Likelihood and coherence backscattering, which can offer a practical comparison between two fields of remote sensing, optical/ multispectral and radar. But the main signature lies in the proximity analysis with which it was able to notice under what natural conditions the methods succeeded in identifying properly built-up areas and which of the metropolitan areas managed to create examples of efficient structures for urban sprawl.

\section{Study area and data}

\section{Study area}

Study areas were represented by 6 metropolitan areas: Baia Mare Metropolitan Area, Braşov Metropolitan Area, Cluj-Napoca Metropolitan Area, Oradea Metropolitan Area, Satu Mare Metropolitan Area and Târgu Mureş Metropolitan Area (Figure 1). These metropolitan areas were chosen on the basis of consulting different scientific articles, technical and scientific reports, development strategies, and information from sites managed by metropolitan associations (FZMAUR, 2013).

The completion of the status of every studied territory is proved both in the specialised literature (Mitrică, B. and Grigorescu, I. 2016) and in the legislation of the country (Law no. $351 / 2001$ ), which is regarding the approval of the National Spatial Plan of Romania. Moreover, the ruling from local public administration describes the principle of functioning as intercommunity development association (Law no. 215/2001). But the current legislation was modified (Law no. 264/2011) and states that the metropolitan area has been defined as an "intercommunity development association established on a partnership agreement between the Romanian Capital City or the first rank cities or the county capitals, and the territorial administrative units from the surrounding area." (Table 1).

Overall, these six functional metropolitan areas contain 113 ATU covering 9,228 $\mathrm{km}^{2}$. These populated areas extend on varied landforms: plain areas, intermountain basins, hill and plateau areas or at the foot of the peaks (Table 2). 


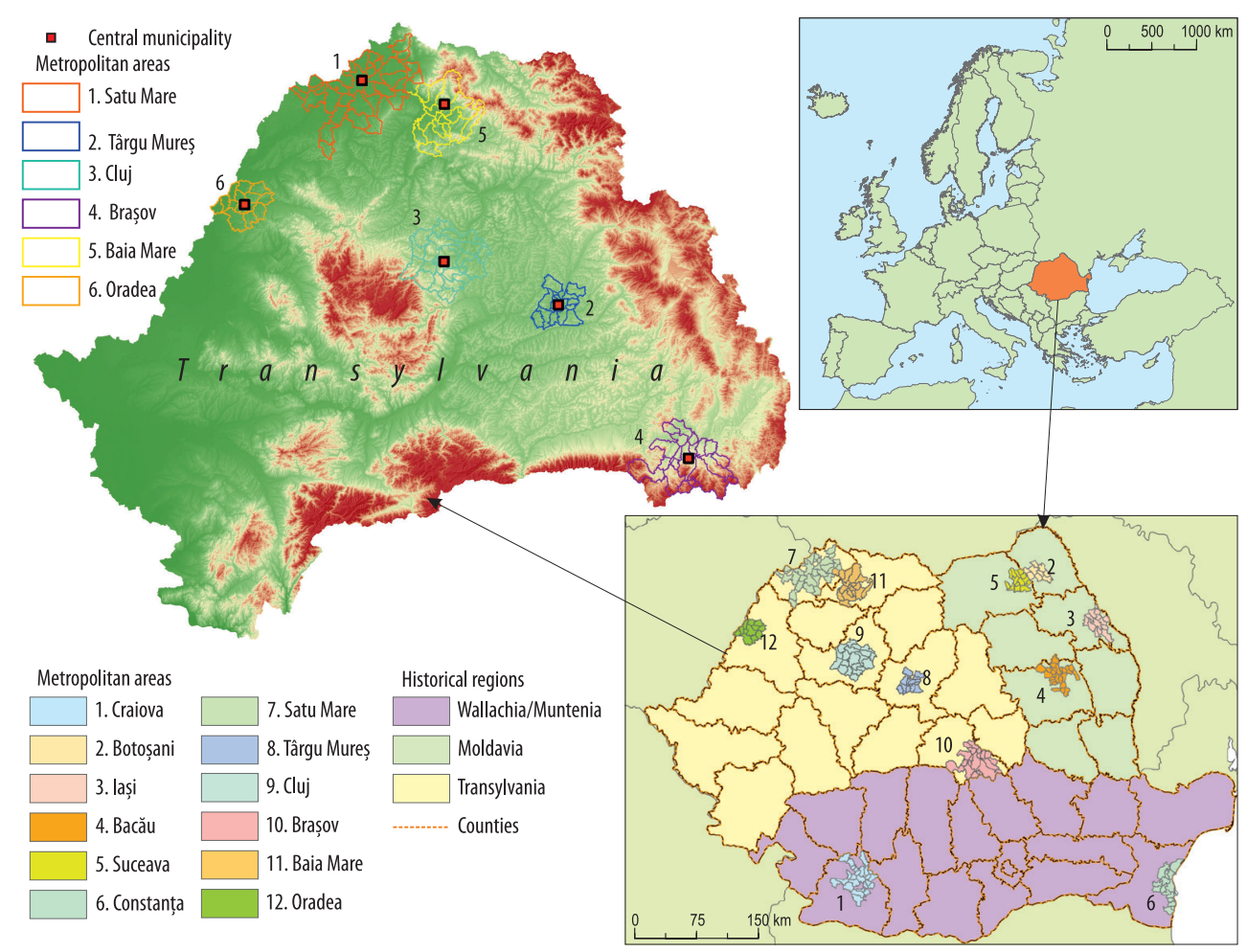

Fig. 1. The location of studied areas: The Romanian metropolitan areas with the three historical regions and metropolitan areas studied in Transylvania overlapping the natural environment.

Table 1. Administrative-territorial units within the metropolitan areas of this study

\begin{tabular}{l|l|l}
\hline \multicolumn{1}{c|}{ Metropolitan areas } & Associated municipalities & \multicolumn{1}{c}{ Associated cities } \\
\hline Baia Mare, 19 members & Baia Mare & $\begin{array}{l}\text { Baia Sprie, Cavnic, Seini, Șomcuta Mare, } \\
\text { Tăuții-Măgherăuș }\end{array}$ \\
Brașov, 18 members & Brașov, Codlea, Săcele & Ghimbav, Predeal, Râșnov, Zărnești \\
Cluj-Napoca, 20 members & Cluj-Napoca & - \\
Oradea, 12 members & Oradea & - \\
Satu Mare, 30 members & Satu Mare, Carei & Ardud, Livada, Tășnad \\
Târgu Mureș, 14 members & Târgu Mureș & Ungheni \\
\hline
\end{tabular}

Table 2. Main socio-demographic indicators of the case study areas

\begin{tabular}{l|c|c|c|c}
\hline Metropolitan area & Area, $\mathrm{km}^{2}$ & Average elevation, $\mathrm{m}$ & Population, $2018^{*}$ & Established \\
\hline Baia Mare & 1,400 & 763 & 243,611 & 2012 \\
Brașov & 1,694 & 1,471 & 477,344 & 2005 \\
Cluj-Napoca & 1,741 & 745 & 435,693 & 2008 \\
Oradea & 750 & 220 & 277,687 & 2005 \\
Satu Mare & 2,241 & 401 & 262,690 & 2013 \\
Târgu Mureș & 657 & 414 & 224,021 & 2006 \\
\hline
\end{tabular}

*National Institution of Statistics (NIS).' 
The chosen areas are located in the historical region named Transylvania. It is known that due to the domination of the Hungarian Kingdom and then of the Habsburgs, this region has had a different economic and social development than the Trans-Carpathian regions. For this reason, it can observe a different architecture of buildings, differences in community behaviour and, thus, in the way of territorial organisation.

The Baia Mare Metropolitan Area is developing more in a North-South direction, in an open field of the inside of the Carpathian arch. Major concentrations of the population are in the Lower Someș Plain and the Baia Mare Basin, at the foot of the Igniș-GutâiLăpuș mountain range. The central municipality is located at $47^{\circ} 39^{\prime} 37^{\prime \prime} \mathrm{N}, 23^{\circ} 34^{\prime} 23^{\prime \prime} \mathrm{E}$ (centroid of the city which was determined from the "Digital Romania" database, more precisely from the point dataset with the localities in Romania), crossed by the Săsar River. The main feature of this city is that it has based on the exploitation and processing of gold and silver ores and of other metals $(\mathrm{Cu}, \mathrm{Pb}, \mathrm{Zn}, \mathrm{Al})$, becoming an important industrial centre during the communist period.

The most developed area of this study is the Brașov Metropolitan Area. This study area presents an asymmetric relief with a lower basin area (Brașov Basin) in the northern part and with a mountainous relief that exceeds 2,000 $\mathrm{m}$ in the South. This area turns the natural elements of mountain tourism (Poiana Brașov and Predeal resorts) and the medieval culture to its advantage. The Brașov city is located at $45^{\circ} 39^{\prime} 34^{\prime \prime} \mathrm{N}, 25^{\circ} 35^{\prime}$ $48^{\prime \prime} \mathrm{E}$, in a scenic area with a breezy climate of intra-mountainous basin.

The Cluj-Napoca Metropolitan Area consists of two rows of communes in an approximately circular-concentric direction around the city at $46^{\circ} 46^{\prime} 6^{\prime \prime} \mathrm{N}, 23^{\circ} 35^{\prime} 28^{\prime \prime} \mathrm{E}$ along the Someșul Mic River in the western part of the Transylvanian Basin. The city has one of the most developed transportation infrastructures in the country, managing to attract numerous industrial and service companies around it, noting the IT component. At the same time, it also holds one of the best performing university centres in the country.

Although it has the lowest number of members, the Oradea Metropolitan Area is one of the most advanced in terms of accessing European funds for urban development. The central municipality is located at $47^{\circ} 3^{\prime} 31^{\prime \prime} \mathrm{N}, 21^{\circ} 55^{\prime} 47^{\prime \prime} \mathrm{E}$ and crossed by the Crişul Repede River. The surrounding urban area is located on a low-altitude ground and slightly higher in the eastern part due to the piedmont plains and the penetration of hilly relief. The Oradea city has learned that the absorption of European Union funds is vital for the urban development of the area.

The largest studied area is the Satu Mare Metropolitan Area. This is mostly extended over a low relief stage, a flood plain (Somes Plain) with a few hills in the southern part and with mountainous features in the northeast (Oaș-Gutâi Mountains). It consists of 30 members, most of which support the county capital with a median position in the territory ( $\left.47^{\circ} 47^{\prime} 9^{\prime \prime} \mathrm{N}, 22^{\circ} 52^{\prime} 32^{\prime \prime} \mathrm{E}\right)$. With the exception of tourism due to thermal and cultural resources, this area has more established for a better using of over 70 per cent of agricultural land of the total area.

Being among the first metropolitan areas established, the Metropolitan Area of Târgu Mureş has the smallest area of the six studied cases and the lowest human resources. The central city, which has the same name, is located at $46^{\circ} 31^{\prime} 51^{\prime \prime} \mathrm{N}, 24^{\circ} 32^{\prime} 17^{\prime \prime} \mathrm{E}$ and is crossed by one of the longest rivers in Romania (Mureș). The area extends into a section of hilly subunits of the Transylvanian Plain and Târnavelor Plateau with the Mureş and Niraj Valley. At the moment, this union of localities tries to forget the socialist period and to develop commercial and recreational components combined with the presence of the machine, chemical and woodworking industry.

\section{Data}

A wide range of data from different sources was used for applying the established meth- 
odology. The first of these were multispectral images with a spatial resolution of $10 \mathrm{~m}$, being acquired by the satellites of the European Space Agency, Sentinel-2A and Sentinel-2B (Copernicus Open Access Hub - https://scihub.copernicus.eu/). One of these remote sensing data was represented by the scenes with a cloud cover of 0 percent at different dates for every study area, depending on the availability of the chosen criteria. The earliest image was obtained from 21 April 2018 for the metropolitan area of Braşov and the most advanced one -6 October 2018 for metropolitan areas of Cluj-Napoca and Târgu Mureş (Table 3).

The second dataset was the Sentinel-1. For each metropolitan area, one pair of SAR images was downloaded at a difference of 12 days, captured by the Sentinel-1A satellite. Every image is an SLC (Single Look Complex - for radar interferometry applications), incorporating signal phase information and covering a $250 \times 250 \mathrm{~km}$ global field and a $5 \times 20 \mathrm{~m}$ spatial resolution (Table 4).

Also, demographic data was used for the year of this study - 2018. The information was obtained from the National Institute of Statistics (NIS - http://www.insse.ro). A digital elevation model (DEM) of $25 \mathrm{~m}$ spatial resolution was used to position the primary information in a consistent and well-documented whole and for the execution of different maps (location, physicalgeographic, cartograms etc.). This DEM was downloaded from the Copernicus database of the European Environment Agency (https:// www.eea.europa.eu/data-and-maps/data/ copernicus-land-monitoring-service-eu-dem).

To make different thematic maps, vector data was used (administrative boundaries, localities, etc.), being available in OpenStreetMap (OSM - https://www.openstreetmap.org/) database and in the Google Earth data imagery as well as a series of orthophoto maps were acquired from 2012 and 2015 from the National Agency for Cadastre and Land Registration (ANCPI) to assess the accuracy of the classifications.

\section{Methodology}

Multispectral images had to run through a series of atmospheric and radiometric correction pre-processing. Downloaded satellite scenes are Level $1 \mathrm{C}$ datasets, and therefore the Bottom-of-Atmosphere (BOA) mode had to be calculated. BOA mode represented the actual reflectance of the areas on the surface

Table 3. Technical details of data sets used in the study-Optical field

\begin{tabular}{l|c|c|l|l}
\hline Metropolitan area & Acquisition date & Orbit & \multicolumn{1}{|c}{ Pass } & Satellite type \\
\hline Baia Mare & 07.05 .2018 & 136 & Ascending & Sentinel-2A \\
Brașov & 21.04 .2018 & 50 & Descending & Sentinel-2A \\
Cluj-Napoca & 06.10 .2018 & 93 & Ascending & Sentinel-2B \\
Oradea & 07.05 .2018 & 136 & Descending & Sentinel-2A \\
Satu Mare & 07.05 .2018 & 136 & Ascending & Sentinel-2A \\
Târgu Mureș & 06.10 .2018 & 93 & Ascending & Sentinel-2B \\
\hline
\end{tabular}

Table 4. Technical details of data sets used in the study-Radar field

\begin{tabular}{l|c|c|l|c}
\hline \multicolumn{1}{c|}{ Metropolitan area } & Acquisition date & Orbit & Pass & Satellite type \\
\hline Baia Mare & $07.05 .2018-19.05 .2018$ & 29 & Descending & Sentinel-1A \\
Brașov & $12.04 .2018-24.04 .2018$ & 51 & Ascending & Sentinel-1A \\
Cluj-Napoca & $28.09 .2018-10.10 .2018$ & 29 & Descending & Sentinel-1A \\
Oradea & $29.04 .2018-11.05 .2018$ & 80 & Descending & Sentinel-1A \\
Satu Mare & $07.05 .2018-19.05 .2018$ & 29 & Descending & Sentinel-1A \\
Târgu Mureș & $28.09 .2018-10.10 .2018$ & 29 & Descending & Sentinel-1A \\
\hline
\end{tabular}


and was calculated from the TOA(Top-of-atmosphere) values, which is already included in Level 1C datasets. This pre-processing step was carried out by using Sen2Cor tool within the SNAP software. Both types of images (optical and SAR) were co-registered and were re-projected in the official coordinate reference system of Romania (Stereographic 1970 - Stereographic azimuthal projection line perspective 1970 with secant plan). To complete the maps, satellite datasets were transferred to the ArcGIS software, where the maps were reclassified to obtain quantitative area data. After that, areas were calculated, providing them cartographic features to complete maps editing. Although many other techniques are superior, such as Object-based Image Analysis (OBIA), Deep learning, Support Vector Machine (SVM) etc., these two main methods of the study, MLC and experimental SAR processing, present a combination of reliability.

For SAR data, every image had to go through a number of steps (FERretTi, A. et al. 2008) using the Sentinel-1 Toolbox (SNAP):

- Splitting the satellite scene for the study area by first choosing the appropriate longitudinal band, followed by the level of coordinates of the analysed area;

- Apply orbit - improving orbital information;

- Calibration - conversion of digital values into physical values, which refers to the retro-reflected signal;

- Deburst - removing no data values;

- Multi-looking - create square pixels of the same size, using one look in range and three looks in azimuth, reducing the noise of radar images and making a virtual band with signal in decibels $(\mathrm{dB})$ to change the contrast of the image using the histogram; in addition, this step will approximate pixel spacing after being converted from slant range to ground range, resulting a mean ground range pixel size of $10 \mathrm{~m}$;

- Terrain correction - applying the RangeDoppler technique, the image will be overturned because initially it has been acquired by the satellite in the mirror, depending on the pass orbit of the satellite; in this step, the image is associated with the country-specific cartographic projection, Stereographic 70 (Figure 2).

Supervised classification represents one of the main techniques being applied to multispectral images. This involves that the user selects pixel samples or pixel groups by visual analysis. The user defines the ranges of spectral values that correspond with phenomena or objects to the real environment. In this study, the probability method named Maximum Likelihood was used (Deng, Y. et al. 2012). All processes were performed with the ERDAS Imagine 2016 software. Fifty pixel samples per land cover were taken for training, resulting in a number of four to six classes. These classes can be assigned to a number of general land cover classes: built-up area, agricultural land, vegetation - broad-leaved forests or coniferous forests, industrial waste, water and snow.

After performing these procedures within SNAP Desktop, two final images will be produced for each Sentinel-1 scene (required for the pair of SAR images). The products of the first two stages will be co-registered in a stack, resulting in a product to which the interferometric coherence will be calculated. After this step, this image will have to perform the deburst, multi-looking and terrain correction stages again. For the final image, it will be making a conversion of the Vertical to Vertical (VV) polarisation band (ABDIKAN, S. et al. 2016) from a linear scale to a logarithmic scale. By deriving a signal in decibels $(\mathrm{dB})$, the histogram of the image can be modified.

Furthermore, the mean signal and the difference signal will be calculated, both of them in decibel units, followed by creating an RGB image, where for the red channel, interferometric coherence will be used, for the green channel - the mean and for the blue channel - the difference. These products can be observed in Figure 3. The urban footprint of the localities, including the builtup areas, will be achieved by creating a new raster through a conditional expression. This will assign two types of pixel value, 0 and 1 , depending on certain thresholds of the average signal in decibels, respectively, accord- 


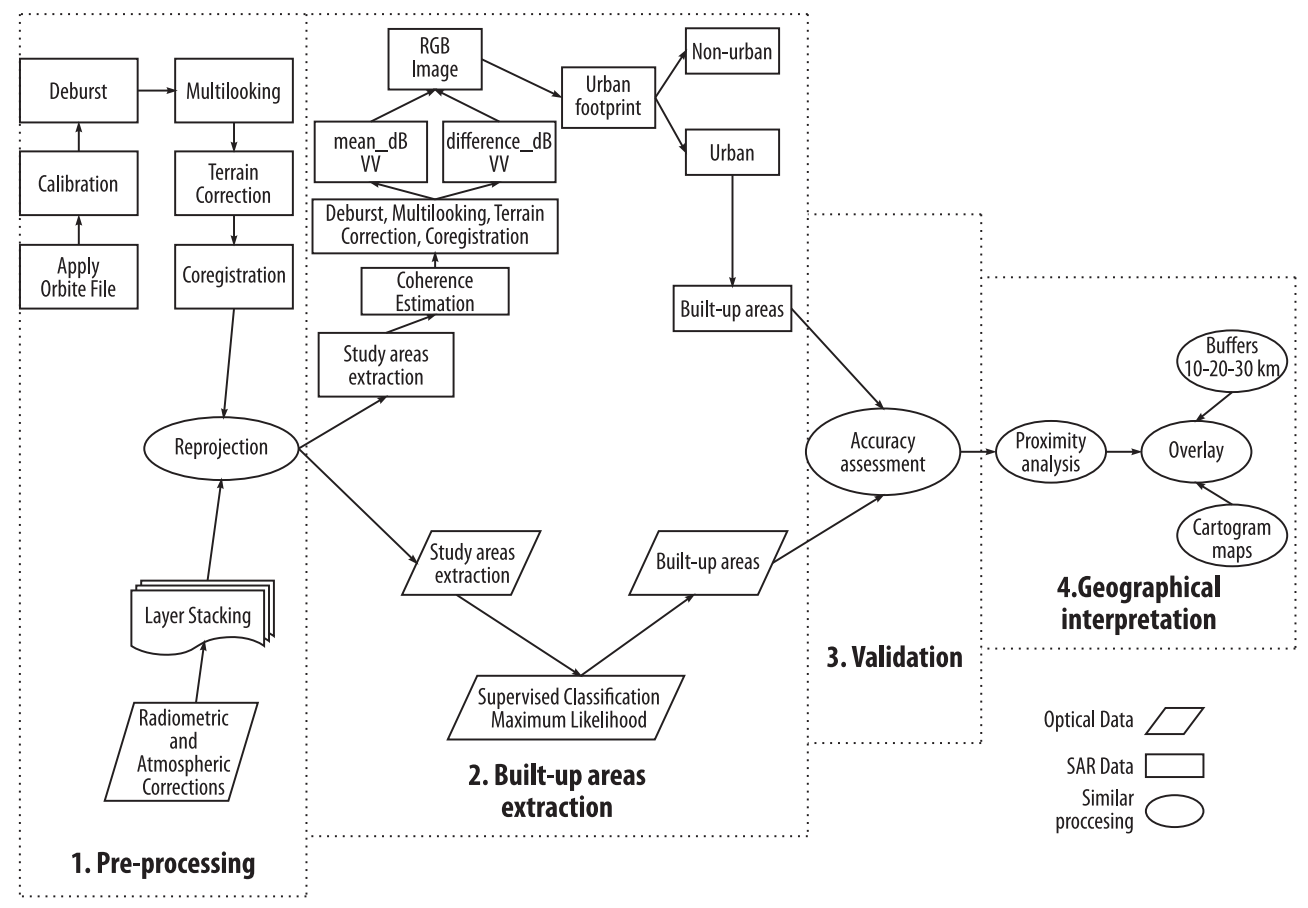

Fig. 2. Methodology flow chart of the study
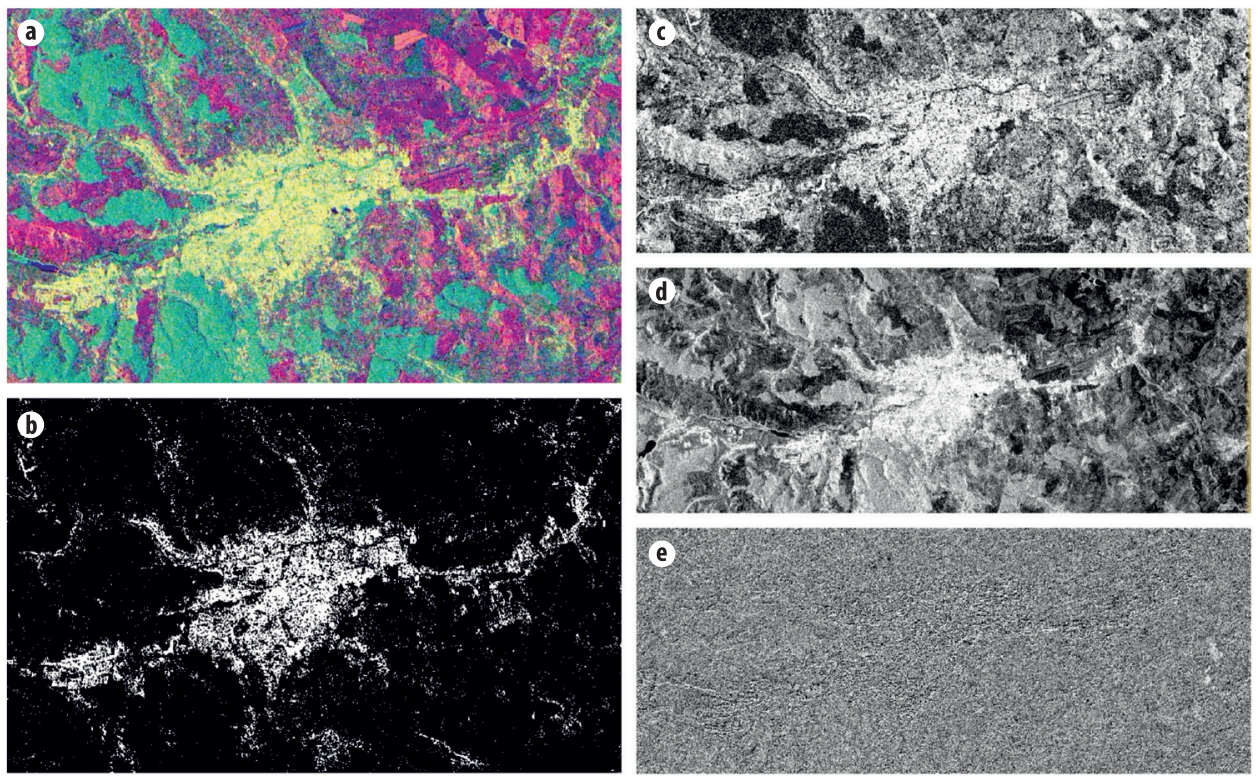

Fig. 3. Final products of pre-processing SAR data sets: $a=R G B$ image; $b=$ urban footprint; $c=$ coherence estimation; $\mathrm{d}=$ mean $\mathrm{dB} ; \mathrm{e}=$ difference $\mathrm{dB}$ for Cluj-Napoca city 
ing to interferometric coherence. The result will be brought to ArcGIS and reclassified to get maps with two classes: urban and nonurban/built-up and unbuilt.

After getting the supervised classifications in the ERDAS Imagine 2016 software, an assessment of the accuracy of classification has performed within the same program, a necessary operation to validate the results. Thus, the software has randomly assigned a number between 200 and 350 points (50 points/class) per classification, depending on the number of detected land cover classes. These points have been transposed to orthophoto maps and georeferenced Google Earth images for validation. For SAR images, the accuracy assessment classification has performed in the ArcGIS software by producing the number of points for two classes. Then, reference values have given and extracted supervised classification values have added to join data in the attribute table to get a matrix of errors (Figure 4). According to the literature
(Congalton, R.G. and Green, K. 2009), the minimum number of points taken to validate the classification should be 50 per category.

Also, a proximity analysis was created in this paper, which is referring to the built-up space from the total area of the metropolitan areas. Once the maps of multispectral images and SAR data have been reclassified, the built-up areas and the areas of the ATUs were calculated and were intersected. In addition, it has traced $10-\mathrm{km}, 20-\mathrm{km}$ and $30-\mathrm{km}$ buffers for a more indepth analysis. The distance of $30 \mathrm{~km}$ from the central municipality is the maximum limit of the metropolitan areas specified in the specialised legislation in Romania (Law no. 264/2011). Thus, the Romanian legislation has taken economic relations (between the members of the area) more into account than natural barriers. The following $20 \mathrm{~km}$ and $10 \mathrm{~km}$ buffers become reference thresholds in this study to observe whether metropolitan areas have been properly established and to monitor the degree of development of the built-up areas. a)
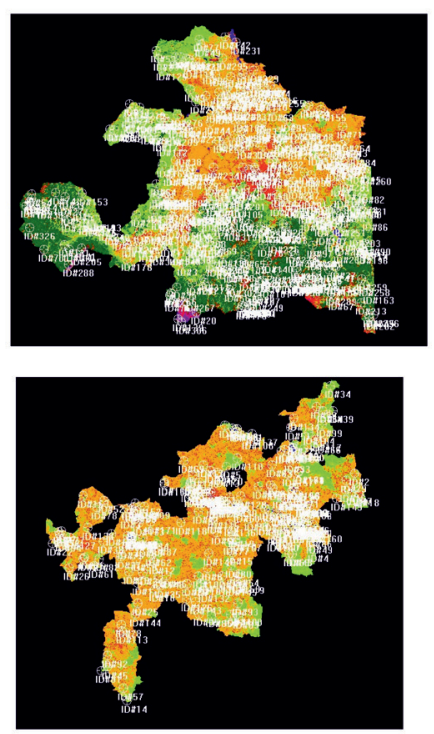

d)
D)
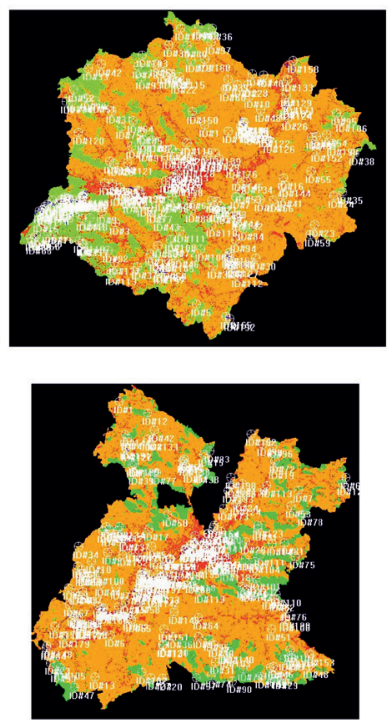

e) c)
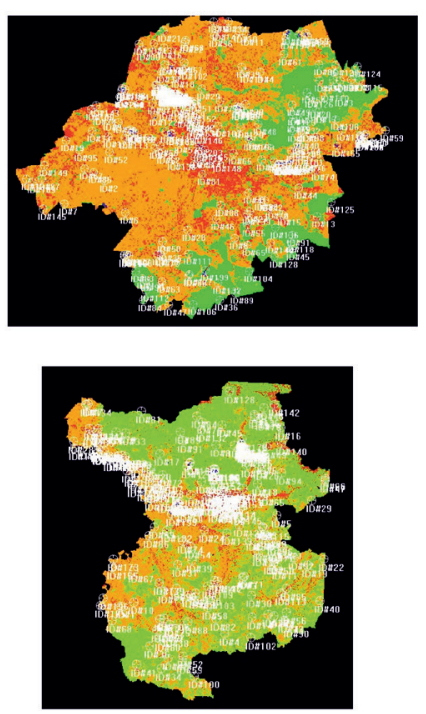

f)

Fig. 4. Distribution of reference points on supervised classifications data in the six metropolitan areas (MA): $\mathrm{a}=$ Brașov MA; $\mathrm{b}$ = Cluj-Napoca MA; c = Oradea MA; $\mathrm{d}$ = Satu Mare MA; e = Târgu Mureș MA; f = Baia Mare MA 


\section{Results}

Most classifications have been able to identify at least four classes of land cover to which some classes were added depending on positioning in a certain landscape or due to the existence of other natural or anthropic factors. This is the case of the Oradea Metropolitan Area, where the industrial waste (ashes and slag) of the Central Heating and Power Station was identified in the northwest part of the city. For the Brașov Metropolitan Area, there is a distinction of vegetation, broad-leaved forests and coniferous forests, plus snow from the highest peaks of the Bucegi Mountains or the Piatra Craiului Mountains. The appearance of the snow class may be due to the acquisition date of the optical image - 21 April 2018, in a mountainous area, between 2,000 $\mathrm{m}$ and the maximum altitude $(2,462 \mathrm{~m})$. Also, some small confusions were observed in these high areas where the recently deforested land was considered as built-up space. In all cases, in addition to the residential space and the most visible buildings, the communication network of localities could be well observed (Table 5).

Regarding the accuracy of the classification, all the cases managed to exceed 80 per cent. According to the literature (Congalton, R.G. 1991), if this value exceeds 80 per cent, there is a high concordance between the classified data and the reference data. The highest values were achieved for Oradea Metropolitan Area, which is the smallest area (see Table 5). For the other larger areas, the values fluctuate from 80 to 87 per cent. This may be due to some identified confu-

Table 5. Accuracy assessment of metropolitan areas of this study-Supervised classification method

\begin{tabular}{l|c|c|r}
\hline \multirow{2}{*}{$\begin{array}{c}\text { Metropolitan } \\
\text { area }\end{array}$} & Overall & User's & Producer's \\
\cline { 2 - 4 } Baia Mare & 94 & 88 & 100.00 \\
Brașov & 82 & 64 & 100.00 \\
Cluj-Napoca & 86 & 74 & 97.37 \\
Oradea & 80 & 60 & 100.00 \\
Satu Mare & 87 & 76 & 97.44 \\
Târgu Mureș & 83 & 68 & 97.14 \\
\hline
\end{tabular}

sions: relatively recently deforested land was considered a built-up area (Figure 5, $a$ and $f$ ), certain disorders with the slope processes, such as landslides or soil erosions (Figure 5, $b$ and $e$ ), which they were identified on agricultural land and which were defined as built-up areas.

Regarding the assessment of accuracy at each category of land cover, the results provide various information about the identified elements. The agricultural land class offers percentages of accuracy between 70 and 80 per cent, because it occupies, in most cases, the largest area of land in metropolitan areas. In contrast, less extensive classes such as water, industrial areas or snow have values of over 84 per cent (Table 6). The areas covered with vegetation offer both efficient results, as in the case of Brașov or Oradea, but also less efficient as in Baia Mare or Cluj. The low percentages mentioned above are due to confusions with agricultural areas, observed especially in rural areas. The accuracy of the built-up areas is close to the overall accuracy, in some places even exceeding it, such as Oradea and Târgu Mureș. The values that exceed a slight 80 per cent belong to the metropolitan areas with a hilly relief (Cluj) or to the predominance of the areas with little very urbanised settlements (Satu Mare).

Also, a proximity analysis of the built-up areas was made at the level of every ATU. It took the form of cartograms in which again, buffers with a radius of $10 \mathrm{~km}, 20 \mathrm{~km}$, and $30 \mathrm{~km}$ are illustrated (Figure 6).

This type of analysis highlights points related to the distribution of the built-up areas in the three deployed boundaries and the natural or spatial causes (the location of settlements within the metropolitan area) that led to these results. Thus, only the Brașov Metropolitan Area managed to exceed 20 per cent of the built-up area $(23.7 \%)$ of the total area of land within a radius of $10 \mathrm{~km}$. The other areas have a percentage between 10-19 per cent. Up to the $20 \mathrm{~km}$ limit, the percentage of built-up area does not exceed 8 per cent for the other areas except the Brașov Metropolitan Area. 
a

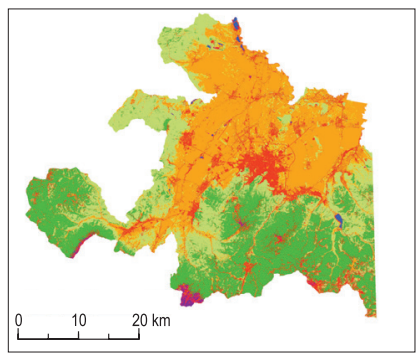

d

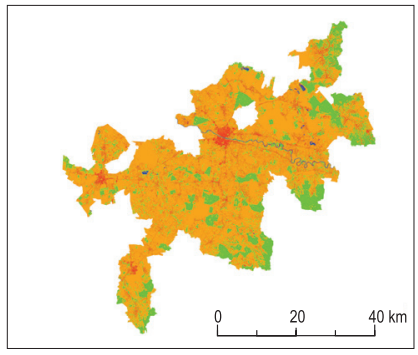

b

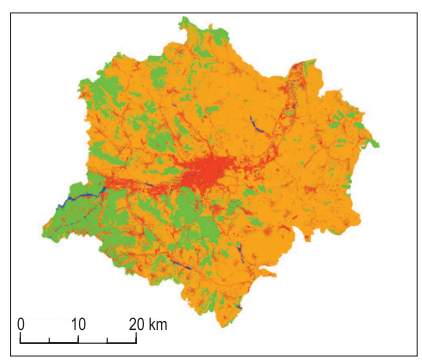

e

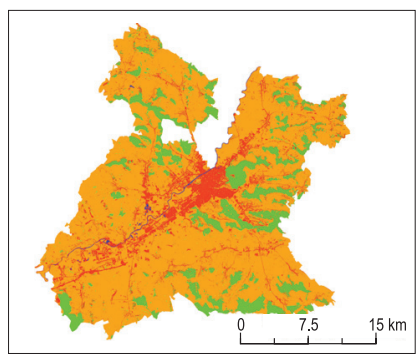

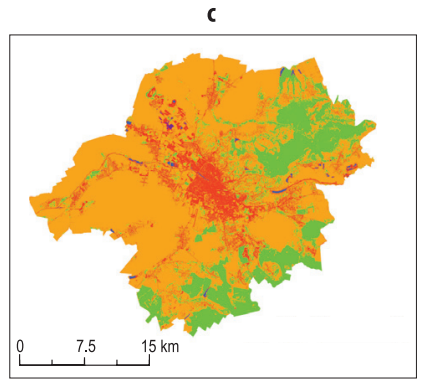

f

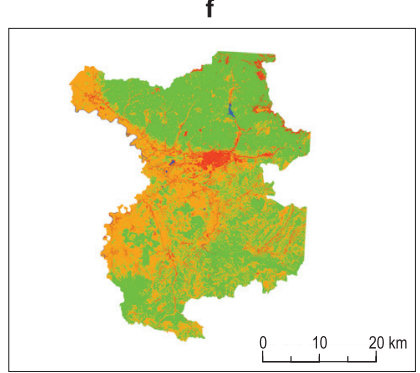

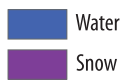

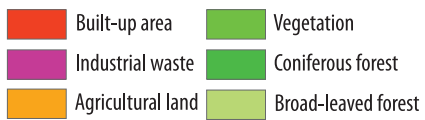

Fig. 5. Supervised classifications (Maximum Likelihood) of the six metropolitan areas (MA): a = Brașov MA; b = Cluj-Napoca MA; c = Oradea MA; d = Satu Mare MA; e = Târgu Mureș MA; f = Baia Mare MA

Table 6. Accuracy assessment of metropolitan areas on land cover classes

\begin{tabular}{l|c|c|c|c|c|c|c}
\hline $\begin{array}{c}\text { Metropolitan } \\
\text { area }\end{array}$ & Overall & $\begin{array}{c}\text { Built-up } \\
\text { area }\end{array}$ & $\begin{array}{c}\text { Agricultural } \\
\text { land }\end{array}$ & Vegetation & Water & Snow & $\begin{array}{c}\text { Industrial } \\
\text { waste }\end{array}$ \\
\cline { 2 - 7 } & \multicolumn{7}{|c|}{ accuracy, \% } \\
\hline Baia Mare & 86 & 82 & 78 & $87^{*} 90^{* *}$ & 98 & 86 & 84 \\
Brașov & 80 & 79 & 73 & 75 & 93 & - & - \\
Cluj-Napoca & 94 & 97 & 90 & 94 & 96 & - & 95 \\
Oradea & 83 & 81 & 74 & 82 & 96 & - & - \\
Satu Mare & 82 & 84 & 77 & 78 & 92 & - & - \\
Târgu Mureș & 87 & 92 & 75 & 86 & 95 & - & - \\
\hline
\end{tabular}

*Broad leaved forest; ${ }^{* *}$ Coniferous forest.

The highest values belong to the central municipality of every area with the maximum values of over $40 \mathrm{~km}^{2}$, in Cluj-Napoca and Brașov, which also have the highest average values. Most of the studied ATUs are in the average category of $3-6 \mathrm{~km}^{2}$ due to weak economic development in member communes, where rural areas still predominate.

Regarding the SAR images, the representation of the built-up area had less conclusive results. This is also due to certain limitations of SAR data, more precisely, not identifying the horizontally built-up area (such as roads, car parks, squares, runways) due to plain textured SAR data and specular backscattering. In addition to this problem, some confusions with marshlands, high humidity areas are added or depending on the slope directions, exactly in the direction of the pass of satellite. These can cause lower values of accuracy, as in the 


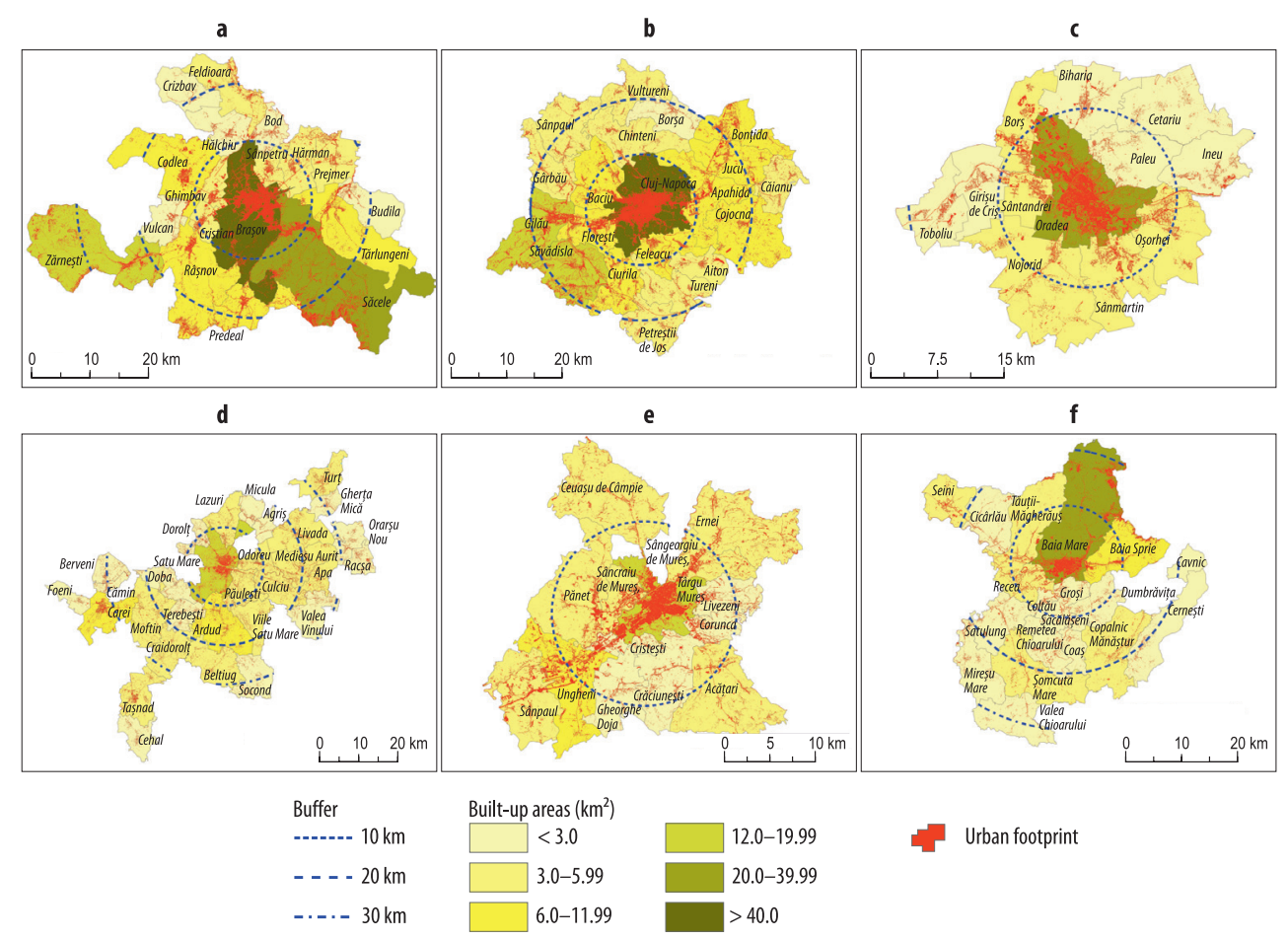

Fig. 6. Distribution of built-up areas at the level of administrative territorial units using Sentinel-2 data: $\mathrm{a}=$ Brașov MA; $\mathrm{b}=$ Cluj-Napoca MA; $\mathrm{c}=$ Oradea MA; $\mathrm{d}$ = Satu Mare MA; e = Târgu Mureș MA; f = Baia Mare MA

case with Oradea Metropolitan Area and Satu Mare Metropolitan Area. These two areas are located in the floodplains, which can produce confusions. For other areas, the situation is acceptable, so that the best values of accuracy were achieved for the areas offering distinct natural elements, such as the Baia Mare Metropolitan Area. Baia Mare city is located in a basin at the foot of the Igniş Mountains, which are covered with broad-leaved forests (Figure 7). The Brașov Metropolitan Area is another excellent example with an overall accuracy of 93 per cent and where the localities in the Brașov Basin are at a short distance from the high peaks of the mountains. The elevation difference is reaching 1,000 metres between the Braşov town and the Tâmpa Hill, which is in the immediate surrounding.

Referring to the proximity analysis, the built-up areas have lower values than the supervised classification method. For the first $10 \mathrm{~km}$, Oradea Metropolitan Area has the highest percentage of built-up area (18.8\%), followed by Baia Mare and Brașov. In the case of this method, there are also isolated values exceeding 10 per cent of the built-up area of the total surface, up to $20 \mathrm{~km}$ and even up to $30 \mathrm{~km}$. This is because of confusion between the analysed category and numerous slope processes with landslides or surface erosions (Figure $7, b$ and $e$ ).

The previously mentioned information is derived from the presentation of data in the form of cartograms. The maximum values are lower than for the other used datasets, more exactly over $20 \mathrm{~km}^{2}$ in the same territories of Cluj-Napoca and Brașov. The degree of confusion can be seen in the case of Cojocna ATU, located in the eastern of Cluj ATU. This fact is due to slope processes, 


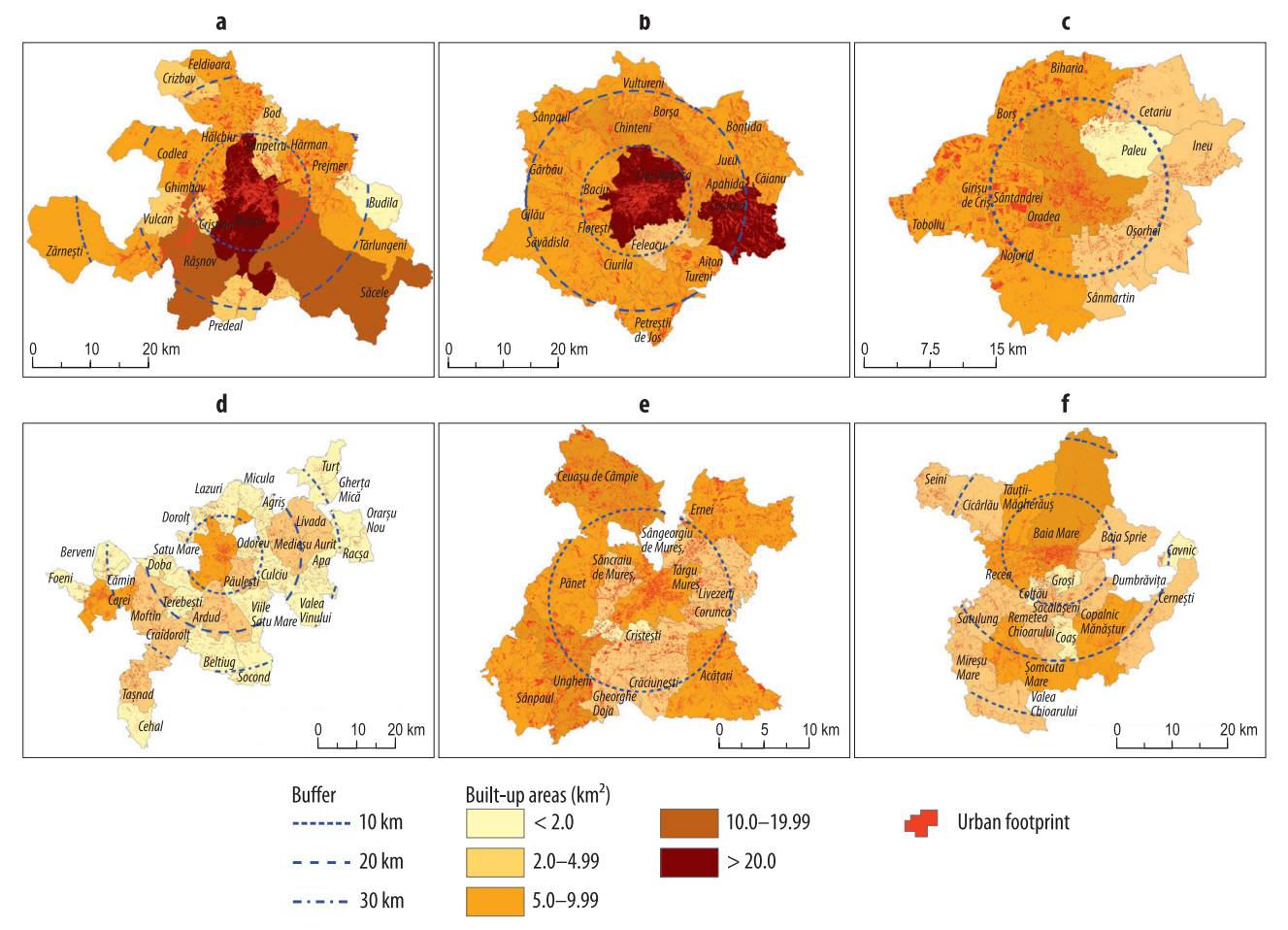

Fig. 7. Distribution of built-up areas at the level of administrative territorial units using Sentinel-1 data: $\mathrm{a}=$ Brașov MA; $\mathrm{b}=$ Cluj-Napoca MA; $\mathrm{c}=$ Oradea MA; $\mathrm{d}$ = Satu Mare MA; $=$ = Târgu Mureș MA; $\mathrm{f}=$ Baia Mare MA

which cause placing it into the same category of over $20 \mathrm{~km}^{2}$ of built-up area. The mean of the values decreases to $2-5 \mathrm{~km}^{2}$, which is better observed in the Satu Mare Metropolitan Area, with a rare built-up area because of the dominance of agricultural land.

\section{Discussions}

In this paper, two methods of processing satellite imagery have been approached having direct applicability. As a result, both Sentinel-2A and Sentinel-2B multispectral images, as well as SAR spatial data acquired by Sentinel-1A, could provide specific information about the built-up areas. In this way, accurate information could be achieved monitoring the level of built-up area in the Transylvanian metropolitan areas in 2018.
Following the accuracy assessment of classification, multispectral images, which were processed by supervised classification have had more reliable results. They have succeeded in identifying certain objects with an impact on the environment - industrial waste, but also to present more precisely street networks and roads. Using specular backscattering and interferometric coherence, the study could get urban footprints with an acceptable degree of accuracy, but also, there are still opportunities for further enhancements. Limitations of SAR data are of a technical nature, mostly confusions with wetlands, slope processes, and the addition of unidentified horizontally built-up areas.

If there is a possibility to compare the results of this study with other studies from different regions but using similar methods, then there are many examples. For exam- 
ple, the values of the overall accuracy of supervised classifications can be analysed in comparison with several Landsat processing results of Brașov (VorovenciI, I. 2017): 88 per cent compared to the 86 per cent of this study. A more practical comparison can be achieved with a study that uses the MLC algorithm on Cluj-Napoca ATU (HoLobÂCă, I.H. et al. 2019). Thus, the study achieved an accuracy of 89 per cent over 80 per cent of this work. So, larger-scale analysis reduces the chances of a higher degree of accuracy, as reported in a study of Okara district, Pakistan $\left(4,419 \mathrm{~km}^{2}\right)$ (Khalil, R.Z. and Haque, S.U. 2017). Thus, in the study mentioned above, although a similar methodology is used to exploit the interferometric coherence based on Sentinel-1 data, the degree of accuracy of the built-up area is only 68 per cent (user's accuracy) and 45 per cent (producer's accuracy). By applying a similar methodology, a much more convincing comparison can be resulted when analysing areas with approximately similar areas. In this regard, studies of the built-up class of two areas in Estonia (Koppel, Z. et al. 2015) manage to achieve values of accuracy between 84 and 88 per cent. In comparison, this study achieved varied and positive values of 78-93 per cent.

\section{Conclusions}

The proximity analysis proved to be broader and efficient to illustrate the current state of development of the Romanian metropolitan areas. Cartograms, buffers, and urban footprints have improved the quality and interpretation of information. Thus, two phenomena are observed. The first one is the concentration of the built-up areas in the proximity of the development poles, achieving an increase in the average built-up area for some regions and, thus, an approach of the member communes to the metropolitan character of the area (Braşov, Oradea, Cluj-Napoca). The other one is the scattering of the built-up space area by the overall average relatively low due to the slow progress of the other communes for the development of the metropolitan area, and because of the predominance of activities in the primary and secondary sectors: agriculture, forestry and industry for Satu Mare, Baia Mare, Târgu Mureş.

The results indicate moderate to high degrees of accuracy values, which are able to reach 94 per cent for multispectral datasets and 93 per cent for SAR data. The supervised classification and the interferometric coherence techniques were applied in an effective manner to studied areas, but the used methodology on multispectral data manage to achieve superior results due to more complete applicability on the characteristics of the data.

Therefore, Romanian metropolitan areas are a source of analysis, not only in terms of administrative, demographic or economic aspects but also from a scientific point of view, in order to highlight the information that contributes to development according to the functioning principles of the cities in the modern world.

\section{REFERENCES}

Abdikan, S., Sanli, F.B., Ustuner, M. and Calò, F. 2016. Land cover mapping using SENTINEL-1 SAR data. The International Archives of the Photogrammetry, Remote Sensing and Spatial Information Sciences XLI-B7. 757-761.

As-Syakur, A.R., Adnyana, I.W.S., Arthana, I.W. and NuARsA, I.W. 2012. Enhanced Built-up and Bareness Index (EBBI) for mapping built-up and bare land in an urban area. Remote Sensing 4. 2957-2970.

Cîmpianu, C. and Corodescu, E. 2013. Landscape dynamics analysis in Iași Metropolitan Area (Romania) using remote sensing data. Cing Continents 3. (7): 18-32.

Congalton, R.G. 1991. A review of assessing the accuracy of classifications of remotely sensed data. Remote Sensing of Environment 37. (1): 35-46.

Congalton, R.G. and Green, K. 2009. Assessing the Accuracy of Remotely Sensed Data: Principles and Practices. Boca Raton, Lewis Publishers.

Copăcean, L., Popescu, C. and Cojocariu, L. 2015. Remote sensing methods for analysing vegetation and urban expansion. Research Journal of Agricultural Science 47. (4): 41-46.

Corbane, C., Faure, J.F., Baghdadi, N., Villeneuve, N. and Petit, M. 2008. Rapid urban mapping using SAR/ Optical Imagery Synergy. Sensors 8. (11): 7125-7143. 
Corbane, C., Pesaresi, M., Politis, P., Syrris, V., Florczyk, A.J., Sollle, P., Maffenini, L., Burger, A., Vasilev, V., Rodriguez, D., Sabo, F., Dijkstra, L. and Kemper, T. 2017. Big earth data analytics on Sentinel-1 and Landsat imagery in support to global human settlements mapping. Big Earth Data 1. (1-2): 18-144.

Corodescu, E. and Cîmpianu, C. 2014. Assessing the spatial differences among some urban expansion driving forces in Constanța Metropolitan Area (Romania). Scientific Annals of "Al. I. Cuza" University of Iaşi Geography Series 60. (2): 77-95.

Deng, Y., FAN, F. and Chen, R. 2012. Extraction and analysis of impervious surfaces based on a spectral un-mixing method using Pearl River Delta of China Landsat TM/ETM+ Imagery from 1998 to 2008. Sensors 12. (2): 1846-1862.

Dewan, A.M. and Yamaguchi, Y. 2009. Land use and land cover change in Greater Dhaka, Bangladesh: Using remote sensing to promote sustainable urbanisation. Applied Geography 29. 390-401.

EEA 2006. The Changing Faces of Europe's Coastal Areas. Copenhagen, Denmark, European Environment Agency. Report No 6/2006.

Esch, T., Marconcini, M., Felbier, A., Roth, A., Heldens, W., Huber, M., Schwinger, M., Taubenböck, H., Müller, A. and Dech, A. 2013. Urban footprint processor - fully automated processing chain generating settlement masks from global data of the TanDEM-X Mission. IEEE Geoscience and Remote Sensing Letters 10. (6): 1617-1621.

Ferretti, A., Monti-Guarnieri, A., Prati, C., Rocca, F. and MAssonnet, D. 2008. InSAR Principles: Guidelines for SAR Interferometry Processing and Interpretation. ESA Publications.

Forkour, G., Dibobe, K., Serme, I. and Tondoh, J.E. 2018. Landsat- 8 vs. Sentinel-2: examining the added value of sentinel-2's red-edge bands to land-use and landcover mapping in Burkina Faso. GIScience \& Remote Sensing 55. (3): 331-354.

FZMAUR 2013. Federation of Metropolitan Areas and Urban Agglomerations in Romania. Bucharest, Studiu POLICENTRIC.

Grigorescu, I., Mitrică, B., Mocanu, I. and Ticana, N. 2012. Urban sprawl and residential development in the Romanian metropolitan areas. Romanian Journal of Geography 56. (1): 43-59.

Grigorescu, I., KucsicsA, G. and Mitrică, B. 2014. Assessing spatio-temporal dynamics of urban sprawl in the Bucharest metropolitan area over the last century. In Land Use/Cover Changes in Selected Regions in the World. Volume V. Eds.: Bičík, I., Himiyama, Y. and Feranec, J., Prague, Czech Republic, IGULUCC, 19-27.

HolobÂcă, I.H., Ivan, K. and Alexe, M. 2019. Extracting built-up areas from Sentinel-1 imagery using landcover classification and texture analysis. International Journal of Remote Sensing 40. (20): 8054-8069.
Huzui, A.E., Călin, I. and Stupariu, P.I. 2012. Spatial pattern analyses of landscape using multi temporal data sources. Procedia Environmental Sciences 14. 98-110.

INS, National Institute of Statistics Romania. 2019. Permanent Resident Population. Bucharest, Romania. Accessed July 2019. http://www.insse.ro.

Ivan, K. 2015. The spatio-temporal analysis of impervious surfaces in Cluj-Napoca, Romania. Geographia Technica 10 (2): 50-58.

Kaimaris, D. and Patias, P. 2016. Identification and area measurement of the built-up area with the Built-up Index (BUI). International Journal of Advanced Remote Sensing and GIS 5. (6): 1844-1858.

KHALIL, R.Z. and HAQUE, S.U. 2017. InSAR coherencebased land cover classification of Okara, Pakistan. The Egyptian Journal of Remote Sensing and Space Science 21. (1): 523-528.

Koppel, K., Zalite, K., Sisas, A., Voormansik, K., Praks, J. and Noorma, M. 2015. Sentinel-1 for urban area monitoring - analysing local-area statistics and interferometric coherence methods for buildings' detection. IEEE International Geoscience and Remote Sensing Symposium (IGARSS), 26-31 July 2015 Milan, Italy. 1175-1178.

Kuemmerle, T., Muller, D., Griffiths, P. and Rusu, M. 2008. Land use change in Southern Romania after the collapse of socialism. Regional Environmental Change 9. (1): 1-12.

Li, H., Wang, C., Zhong, C., Su, A., Xiong, C., Wang, J. and LiU, J. 2017. Mapping urban bare land automatically from Landsat imagery with a simple index. Remote Sensing 9. (3): 249.

Lillesand, T.M. and KiEfER, R.W. 1994. Remote Sensing and Image Interpretation. $3^{\text {rd }}$ Edition. Hoboken, N.Y., John Wiley and Sons, Inc.

MA, Y. and $\mathrm{X}_{\mathrm{U}}, \mathrm{R}$. 2010. Remote sensing monitoring and driving force analysis of urban expansion in Guangzhou City, China. Habitat International 34. (2): 228-235.

Minai, B., Nistor, C. and Simion, G. 2015. Post-socialist urban growth of Bucharest, Romania - a change detection analysis on Landsat imagery (1984-2010). Acta Geographica Slovenica 55. (2): 223-234.

Mitrică, B. and Grigorescu, I. 2016. Dezvoltarea urbană şi ariile metropolitane (Urban development and metropolitan areas). In Romania. Natura si Societate. Eds.: Balteanu, D., Dumitrascu, M., Geacu, S., Mitrica, B. and Sima, M., Bucuresti, Editura Academiei Romane, 250-291.

Mucsi, L., Liska, C.M., Henits, L., TobaK, Z., Csendes, B. and NAGY, L. 2017. The evaluation and application of an urban land cover map with image data fusion and laboratory measurements. Hungarian Geographical Bulletin 66. (2): 145-15.

Padmanaban, R., Bhowmik, A.K., Cabral, P., Zamyatin, A., Almegdadi, O. and Wang, S. 2017. 
Modelling urban sprawl using remotely sensed data: A case study of Chennai City, Tamilnadu. Entropy 19. (4): 163.

Pesaresi, M., Corbane, C., Julea, A., Florczyk, A.J., Syssis, V. and Sollle, P. 2016. Assessment of the added-value of Sentinel-2 for detecting built-up areas. Remote Sensing 8. (4): 299.

Sandric, I., Mihai, B., Savulescu, I., Suditu, B. and Chiтu, Z. 2007. Change detection analysis for urban development in Bucharest-Romania, using high resolution satellite imagery. Urban Remote Sensing Joint Event 2007. 1-8.

Serertekin, A., Marangoz, A.M. and Akcin, H. 2017. Pixel-based classification analysis of land use land cover using SENTINEL-2 and LANDSAT-8 data. The International Archives of the Photogrammetry, Remote Sensing and Spatial Information Sciences XLII-4/W6. 91-93.

VorovenciI, I. 2017. Analysis of the changes in the metropolitan area of Brașov, Romania, using Landsat multi-temporal satellite image. Environmental Engineering and Management Journal (EEMJ) 16. (2): 303-316.
XU, H. 2010. A new index for delineating built-up land features in satellite imagery. International Journal of Remote Sensing 29. (14): 4269-4276.

Yuan, F., Sawaya, K.E., Loeffelholz, B.C. and BAUER, M.E. 2005. Land cover classification and change analysis of the Twin Cities (Minnesota) Metropolitan Area by multi-temporal Landsat remote sensing. Remote Sensing of Environment 98. (2): 317-328.

ZAKERI, H., YAMAZAKI, F. and LiU, W. 2017. Texture analysis and land cover classification of Tehran using polarimetric Synthetic Aperture Radar imagery. Applied Sciences 7. 452.

ZHA, Y., GAO, J. and NI, S. 2003. Use of normalized difference built-up index in automatically mapping urban areas from TM imagery. International Journal of Remote Sensing 24. (3): 583-594.

Zoran, M. and Weber, C. 2007. Use of multi-temporal and multispectral satellite data for urban change detection analysis. Journal of Optoelectronics and Advanced Materials 9. (6): 1926-1932. 